\title{
REFLEXIONES SOBRE MARGINALIDAD
}

Creo que antes de abordar un tema tan vasto cabe intentar en primera instancia una sistematización de los conceptos de marginalidad que surgen de la época de mi especialidad.

La referencia a una época nos parece indispensable porque cada momento engendra sus propios marginales -término cuya validez analizaremos luego- de acuerdo a las pautas que estructuren ese período.

Por cierto, los márgenes tienen connotación temporal y regional, los conceptos cambian según épocas y lugares. Pero hay algunos presupuestos de rechazo y exclusión que perduran a través de las edades. Creo que es lícito intentar llegar a ellos a través de enfoques parciales.

Antes de nada creo importante realizar una precisión general que implica insistir en una clasificación que me ocupará en su momento: la distinción entre alógenos y marginales ${ }^{1}$.

Para mí el alógeno es «lo que se produce y permanece como otro o lo que se transforma en otron ${ }^{2}$. Mientras que los marginales son quienes -aun cuando pertenecen o participan de un cuerpo social- no se encuentran identificados con la totalidad de las pautas y normas de ese cuerpo, los que no responden al modelo que éste se da. Son los aceptados o quienes aceptan una sociedad de manera parcial, parcialización que los lleva a situarse en una posición ex-céntrica, no hay apicidad en ellos, no hay posición central y eminente, para ellos es el margen y el límite. Que atravesarán en ciertas circunstancias para transformarse en otros.

A menos que la situación pueda revertirse y puedan ser aceptados por la sociedad que los margina integrándose totalmente. Esta situación podrá lograrse mediante concesiones y aceptaciones ya de uno u otro de los términos entre quienes se establece la relación, ya de parte de ambos.

Son individuos que se apartan de las pautas de la sociedad y que no se adhieren a la mentalidad de esa sociedad, que se apartan de la unanimidad. Puesto que la mentalidad «es el resultado de la experiencia de todos» representa el lazo entre la realidad nouménica y la subjetividad individual ${ }^{3}$.

1 Nilda Guglielmi, Marginalidad en la Edad Media, Buenos Aires, Eudeba, 1986, p. 9 y ss.

2 Id., p. 11.

3 Gaston BOUTHOUL, Les mentalités, París, P.U.F., 1958, p. 32. Considero insuficiente la explicación de los párrafos subsiguientes. Tendríamos que haberla desarrollado de manera más crítica y matizada, así como haber tratado los conceptos de historia social y de imaginario. Pero creo que hubiera sido excesivo. Preparo de todo ello un análisis más amplio y profundo. 
La mentalidad es el resultado de las "síntesis concomitantes» de que hablaba Durkheim, «es decir, la eclosión ante la presión de un gran número de gentes». Que se caracteriza por ser común a los miembros de una misma civilización por su extrema estabilidad y por ser el lazo más resistente que liga al individuo a su grupo.

Muchas son las definiciones que podríamos aportar sobre el término mentalidad. La boga, en los últimos tiempos de la historia de las mentalidades, ha determinado muchas discusiones acerca de la definición a la que se agrega la relativa a la licitud o valor de esa bistoria de las mentalidades conectada con el imaginario de una sociedad, concepto también éste de difícil aprehensión.

Jacques Le Goff nos pone en guardia acerca de esta nueva tendencia de la historia al titular un ensayo al respecto: Las mentalidades. Una bistoria ambigua ${ }^{4}$. Hemos hablado de moda, característica que subraya Le Goff al citar una frase de $\dot{A}$ la recherche du temps perdu. Du côté de Guermantes: «Mentalité me plaît. Il y a comme cela des mots nouveaux qu'on lance». Es posible que esta historia de las mentalidades todavía presente un campo poco delimitado. Le Goff parecería sin embargo afirmar el elemento positivo al titularla una historia-encrucijada, lo que comportaría determinar un viraje importante en los estudios históricos. Esta indefinición de que hablamos está, sin duda, dada por la extensión de ese campo, dada la petición de la historia a otras disciplinas. La historia de las mentalidades es omnívora o-según la calificación de Vovelle- bulímica'. Es decir, se acerca a la historia religiosa, a la literatura, a la historia de las ideas, al folklore, a la etnología para incorporar muchos de sus resultados. Se apodera de fuentes que tradicionalmente no le pertenecen, plantea de peculiar manera temas con la ayuda de todas esas disciplinas... Enriquecimiento del campo histórico, exigencias para el historiador que, al invadir territorios ajenos, corre el riesgo de improvisar roles. Enriquecimientos y peligros.

No corresponde que profundicemos aquí límite y metodología. En cambio, pensamos que -aun a riesgo de caer en la imprecisión- hemos de acercarnos a la noción-base qué es mentalidad.

Le Goff dice que «Las mentalidades mantienen con las estructuras sociales relaciones complejas, pero sin estar separadas de ellas" ${ }^{6}$. Esta conexión de las mentalidades con la sociedad la relaciona prietamente con la historia social.

Sin duda, hablar de la mentalidad de una época nos lleva a otras imprecisiones que no trataremos de superar en este artículo. En cada época coexisten mentalidades diversas según los diferentes grupos sociales, en cada época debemos analizar la posibilidad de transformaciones de la mentalidad imperante.

De todas maneras -y a pesar de todas estas observaciones- creemos necesario tratar de acercarnos a algunas definiciones de mentalidad.

Según Le Goff' "Mentalidad recubre pues un más allá de la historia, pretende satisfacer las curiosidades de historiadores decididos a ir más lejos».

\footnotetext{
4 Jacques LE GOFF, Las mentalidades. Una bistoria ambigua en «Hacer la historias bajo la dirección de Jacques Le Goff-Pierre Nora, 3 vols. Barcelona, Editorial Laia, 1980, III, p. 81.

3 Michel VOVELLE, Ideologias y mentalidades. Barcelona, Editorial Ariel, S.A., 1985, p. 13.

6 Ob. cit., p. 94.

7 Id., p. 82.
} 
La mentalidad está constituida por las ideas, opiniones, creencias, que constituyen el patrimonio de todos, ideas que han perdido su racionalidad, operan, actúan. Son el conjunto de «ideas corrientes, de ideas operativas, que funcionan efectivamente en una sociedad, que no han sido nunca expuestas de manera expresa y sistemática, que no han sido nunca ordenadas ni han sido motivo de un tratado, pero que sin embargo nutren el sistema de pensamiento y rigen el sistema de la conducta del grupo social" ".

Esas ideas actúan con eficacia pues tienen el consenso de todo el grupo social, consenso tácito, del que gozan sin que sean sometidas a juicio. $O$ sea que son ideas que han perdido racionalidad, que se han desprendido «del sistema explicativo [...] transformándose en ideas vulgares" ?.

Creo que la opinión de José Luis Romero es una excelente síntesis de lo que hemos expuesto hasta ahora. Define así: «La mentalidad es algo así como el motor de las actitudes. De manera poco racional a veces, inconsciente o subconscientemente, un grupo social, una colectividad, se planta de una cierta manera ante la muerte, el matrimonio, la riqueza, la pobreza, el amor, el trabajo..." ${ }^{10}$.

Es evidente que quien rompe con las creencias colectivas es mirado con sospecha y condena. Sólo en situaciones excepcionales podemos encontrar una actitud admirativa o de aceptación respecto de esos reales o aparentes transgresores.

Creo importante hacer estas consideraciones sobre marginal o alógeno porque, hasta hace unos veinte años, el término de marginal no aparecía entre los utilizados por los historiadores ".

Se empleaba para aludir a ellos -en el mundo medieval podía tratarse de herejes, pobres, extranjeros, locos, leprosos... - el término de excluidos ${ }^{12}$.

Creo que podemos emplear la palabra excluidos poniéndola en relación con ámbitos de participación. Serían los excluidos de..., de un cierto núcleo, de un cierto lugar, del goce de ciertos derechos...

Pero considero que la palabra, usada sin más, da un sentido de absoluto demasiado tajante, un sentido de no-pertenencia, de inexistencia de lazos que no responde a la realidad.

Jacques Rossiaud en su libro sobre la prostitución en la Edad Media ${ }^{13}$ dice vehementemente que «las prostitutas no eran marginadas en su ciudad; simplemente desempeñaban una función». Creo que el autor se ha sentido obligado a estampar esta frase por la carga de exclusión que otorga al término.

13.

8 José Luis ROMERO, Estudio de la mentalidad burguesa, Madrid- Buenos Aires, Alianza Editorial, 1987, p.

9 Id., p. 13.

10 Id., p. 17.

11 Pongo como ejemplo, Jacques LE GOFF, La civilisation de l'Occident médiéval, Paris, Arthaud, 1964, cap. VIII. La sociéré cbrótienme (Xe-XIlle siòcle), p. 387 y ss., «Les exclus: hérétiques, lépreux, juifs, sorciers, sodomites, infirmes, étrangers, déclassés.w. A.A.V.V., Exclus et systèmes d'exclusion dans la littérature et la civilisation médiévales, Aix-en-Provence, Édition CUERMA, Université de Provence, 1978.

12 Como ejemplo reciente, Françoise BÉRIAC, Histoire des lépreux au Moyen Age. Une société d'exclus, París, Imago, 1988.

13 Jacques ROSSIAUD, La prostitución en el Medioevo, Barcelona, Ed. Ariel, S.A., 1986, p. 49. 
Pensamos que ni las prostitutas ni el loco-tonto, ni el verdugo eran excluidos. Formaban parte del cuerpo social. Simplemente se los colocaba en los límites del mismo pero dentro de él.

Recordemos el trabajo de Jacques Le Goff Métiers licites et métiers illicites ${ }^{14}$ en que nos habla de los "vilia officia" («los viles oficios") sobre los que pesan interdicciones seculares, el tabú de la sangre, de la impureza, del dinero... Numerosas profesiones mal vistas, desde los cirujanos y barberos a los verdugos y prostitutas, desde los tintoreros (los uñas azules, por ejemplo) a los cocineros, desde los prestamistas a todos los que lograban dinero merced a un «turpe lucrum». Todos estaban dentro del cuerpo social -que inclusive necesitaba de ellos- aunque ciertamente no los colocaba en posición eminente.

Por lo demás, siento que el término marginal es insuficiente. Es necesario que logremos palabras de una mayor precisión o que atribuyamos un contenido determinado a las variantes que logremos.

De ordinario, la carga que recibe el término marginal es la de individuo rechazado -no expulsado- de un núcleo mayor. Es como si a éste se le diera el total poder de decisión y el marginal aparece como desprovisto de toda decisión y de toda acción.

Se considera a los marginales afectados por una sanción mayoritaria, se los coloca siempre en la posición de sufrir una situación que, además, muchas veces se considera simplemente exclusión.

Creo que también hemos de hacer otra reflexión sobre estas frases. Hemos empleado los términos ya en singular ya en plural. Ello nos lleva a pensar en que el marginal podía ser un caso aislado o podía constituir un grupo, es decir, podía darse marginalidad individual o grupal.

De todo esto surge el hecho de que el problema de la marginalidad no debe perder nunca de vista un juego sumamente flexible y matizado entre dos entidades, el núcleo o grupo mayor que impone pautas, conductas y actitudes y el individuo o grupo menor que puede experimentar dificultades -circunstanciales o permanentes- en su inserción total en ese grupo.

Pienso que en ese juego de integración debemos destacar por un lado la aceptación -pretendida o deseada- de la inmutabilidad de una sociedad y, por el otro, la insistencia y esfuerzo para que esa sociedad se transforme. Eso implica subrayar deseos y voluntades de uno y otro lado. Voluntad de uniformizar, de hacer coherente, sin peculiaridades, sin estridencias; todo debe conservar tono y mesura, en suma, adaptarse al modelo que da el grupo mayor. Voluntad de acallar, apartar, modificar, reincorporar en caso oportuno o expulsar definitivamente a quien no cumpliera con esas expectativas.

Nos encontramos, por el otro lado, con quienes expresarán su voluntad de modificar la sociedad que no los incorpora plenamente. A veces, ese deseo de modificar podrá expresarse en asentimiento a la propia modificación como condición aceptada para integrarse y perder lo que en tal caso se considera estigma de

14 Jacques LE GOPf, Pour un autre Moyen Afe, Paris, Gallimard, 1977, p.91 y ss. 
marginal. Esto nos lleva a pensar en que el individuo así discordante puede serlo involuntaria o voluntariamente.

En el primer caso, su desarmonía es sufrida, en el segundo es buscada.

La marginalidad puede ser negativa o negativo-positiva, según el punto de mira en que nos ubiquemos.

De ordinario, la sociedad signaba a aquellos de quienes se debía desconfiar pero también quienes rechazaban su participación en la sociedad se singularizaban por medio de signos exteriores. Recordemos el viejo libro de Ulysse Robert, Signes d'infamie au Moyen Age ".

Yo, por mi parte, he aludido en La ciudad medieval $y$ sus gentes ${ }^{16}$ a las particularidades vestimentarias de las prostitutas y su marginalización en general. También me he ocupado de la rouelle o círculo partido que los judíos debían llevar según la voluntad de reyes y autoridades ${ }^{17}$.

De los muchos ejemplos posibles del signo como singularización, tomemos lo que nos ofrece el Tratado de Ibn Abdun de Sevilla (siglo XII). Se prohibe en uno de los apartado que «alcabalero, policía, judío ni cristiano lleve atuendo de persona honorable, ni de alfaquí, ni de hombre de bien...». Considera que deben ser aborrecidos. No son dignos de recibir el saludo «La paz sea sobre tín puesto que -según el autor- están poseídos por Satán. Ese desdén evidente se endurece aún más pues se sugiere que habrán de «llevar un signo por el que sean conocidos, por vía de humillarlos» ${ }^{18}$.

Las mujeres de casas llanas (dar al-jarach) según el Tratado tendrán que observar actitudes determinadas; además se prohibirá a las mujeres honradas que «usen los mismos adornos que ellas" ${ }^{19}$.

Signo, modo de apartamiento, ya sea positivo o negativo. En los ejemplos mencionados siempre son negativos, humillantes, tendentes a la alerta y a la separación.

Pero hemos dicho que, a veces, ese signo expresaba la decisión de singularizarse por parte de quienes no acataban las pautas que la sociedad imponía.

Así, por ejemplo, en la fiesta de los locos, los participantes tomaban apariencias extrañas, sobre todo de animales. El loco-tonto se tocaba con su gorro de cascabeles y empuñaba la marotte. San Francisco eligió cubrirse con el vestido de los campesinos de su tiempo. Es decir que, a veces, la singularización, por medio del signo exterior, era buscada.

El signo era pues uno de los elementos de apartamiento. Otro, podía ser la determinación del ámbito de residencia, de trabajo, de circulación. Prostitutas, hebreos, leprosos... sufrían esa cesuración, ejercida de manera constante o determinada por tiempos y por ámbitos sagrados. Pero no olvidemos que, en ocasiones,

is Ulysse ROBERT, Les sigmes d'infamie an Moyen Age: juifs, sarrazins, bévétiques, lépreux, cagots, filles publiques, París, Honoré Champion, 1891.

16 Nilda GUGLIELMI, La cinded medieval y sus gentes, Buenos Aires, Fundación para la Educación, la Ciencia y la Cultura, 1981.

17 Ver Marginalidad on la Edad Media, ed. cit., p. 429 y ss. La condición de los judíos medirvales.

18 E. LÉVI-PROVENÇAL y Emilio GARCÍA GÓMEZ, Sevilla a comienzos del siglo XII. El tratado do Ibn Ábdwn, Madrid, Moneda y Crédito, 1948, p. 157 \& 169. 
también el apartamiento era buscado y querido. El santo eremita se aleja del lugar habitado: a veces la cesura que impone es total, otras parcial, pero lo que destacamos es la voluntad ejercida en el retraimiento.

En la actualidad, ha aparecido otro término que disputa la primacía a marginalidad. Se habla de alteridad ${ }^{20}$. Creo que -aunque expresivo- es poco matizado. Es poco apto para recibir la necesaria flexibilización que la riqueza de un ámbito social impone. Puede ser empleado pero no puede ser el único elemento de un vocabulario que hable de la diferenciación en el seno de una sociedad.

Veo el término de alteridad con una gran carga psicológica individual y con menos connotaciones sociales e históricas. Creo, sobre todo, que es demasiado tajante. El individuo o grupo que no coincide con los modelos dados por una sociedad es otro, así, de manera tajante y absoluta. Pienso, en cambio, que si adoptamos los términos de marginal y alógeno -que en suma también es el otropodemos acercarnos a la vida social con instrumentos de análisis más ricos. Además, considero que esos términos enunciados en absoluto han de relativizarse -en la adjetivación corespondiente- para lograr un mayor número de variantes y, por tanto, un espectro más amplio de situaciones posibles. Tal vez tendríamos que establecer un vocabulario que nos permita aludir a estas situaciones sin que se imponga cada vez la necesidad de aclaraciones. Entendiendo que estableceremos una convención.

Por un lado tendríamos al marginado o marginalizado; por el otro, al marginal y al disidente. Cargaríamos a los dos términos primeros con el sentido de apartamiento por sanción del grupo mayor; en el segundo caso, la separación provendría de la voluntad del individuo o grupo menor.

El marginado o marginalizado puede también tener varias conductas posibles. Una, de aceptación del papel que la sociedad le otorga, por tanto, permanencia en un status, situación o condición determinadas. Esto por diversos motivos, por falta de conciencia de esa situación, por aceptación resignada, por conveniencias de distinto tipo. Otra conducta puede ser, en cambio, la formulación clara de su situación y la reacción necesaria para revertirla. En tal caso, nos encontramos con el disidente.

Pero tendríamos que destacar otras posibles soluciones. Podemos encontrarnos con un disidente evidente y declarado o con un disidente encubierto. Éste puede lanzar su mensaje que implica su voluntad de transformación de la sociedad aun permaneciendo aparentemente inmutable. Sería una forma de enmascaramiento.

Lo que nos interesa destacar por sobre todo es la posibilidad de transformación, señalar la dinámica de una sociedad.

El marginal sería quien se pone o permanece voluntariamente en los límites de una sociedad porque no participa totalmente de su vida y valores por mil motivos: puede ser el viajero, que aunque alógeno pasa por un ámbito que no quiere ni

19 Id., p. $156 \& 168$.

20 En general, ver L'image do l'autre. Ésrangers-Minoritaines-Marginawx, sous la direction d'Hélène Ahrweiler, «16e. Congrès International des Sciences Historiques,» 2 vols., Stuttgart, 1985. En esa obra colectiva, Eloy BENITO RUANO-Juan Ignacio GUTIÉRREZ NIETO, Otros» cristianos. Conversos en Espatta, siglos XV-XVII, I, pp. 61-89. Además: Eloy BENITO RUANO, De la alteridad en la bistoria, Madrid, Real Academia de la Historia, 1988. 
pretende modificar, puede ser el extranjero residente, el aliado que se incorpora circunstancialmente... La intención también hemos de verla ejercida en el tiempo. Hay situaciones que son puntuales, que se resuelven en breve plazo, otras que tienen mayor duración y que pueden desembocar en soluciones definitivas o prolongarse. Ésta es -como veremos- una premisa que se ejerce respecto de todos los casos de desajuste.

El disidente sería aquel que -de manera neta o velada- expresa su situación de no-participación y esa explicitación lleva además un deseo de modificación del grupo mayor. En este caso es el individuo o grupo menor el que ofrece un modelo a la sociedad al que pretende que ésta se adapte. Destaquemos que el disidente puede ser revolucionario o conservador y nostálgico. Puede indicar pulsiones hacia adelante o hacia atrás. Las modificaciones propuestas pueden implicar una transformación radical o la vuelta a una situación ideal anterior que se considera perdida o quebrada.

El problema de definir la alteridad o marginalidad y alogeneidad está en relación con el núcleo que piensa, delimita y expresa su identidad.

A nosotros no nos interesa el problema sino a partir de un marco histórico determinado, el mundo medieval; por tanto tenemos que delimitar las pautas que informan ese mundo, las tendencias que lo estructuran.

Antes de ver cómo se regulan e interactúan, importa establecer una norma general que -creemos- siempre defiende la validez del sistema de valores.

El núcleo que reflexiona acerca de su naturaleza, se piensa como un cosmos u orden. Y considera que lo que está fuera de él -un fuera que no tiene sentido físico sino de adhesión- constituye una a-cosmia, un desorden. Esta es una diferenciación tajante que podría justificar la división única en mismidad y alteridad pero a la misma podríamos añadir valores relativos de tal manera ese cosmos reconocería desajustes parciales o circunstanciales que determinarían una marginalidad que podría ser corregida o que se propondría serlo. Es decir, desajustes menores en que el grado de intensidad en la desarmonía no lleva a la ruptura, a la alteridad, a la alogeneidad.

Al hablar de estas pautas o sistema que sustenta un determinado marco de referencia podemos caer en el error o en el recurso cómodo de entender que ese sistema es inmutable o, por lo menos, permanece coherente durante mucho tiempo. Por ello, acertaremos en mayor medida cuando nos propongamos la solución de un caso en la breve duración. Más difícil es conocer cuándo se producen los giros de opinión, el cambio ideológico en una sociedad dada y determinar su grado de aceleración.

En realidad, tendríamos que preguntarnos por la flexibilidad y capacidad de cambio del «imaginario" de una sociedad, es decir, la imagen que una sociedad se hace de sí misma.

Nos interrogamos sobre la tendencia más clara de una sociedad, en general podemos decir que las características de fijación son las que predominan, con una gran fuerza de anclaje en valores constituidos y afirmados. Queda por señalar en cada caso, la violencia de las tendencias disonantes y la rapidez del cambio.

Por tanto, la transformación de la conciencia e imagen de sí de una sociedad 
implica la que se tiene de los grupos extraños y marginales. En general -marginales, marginados, marginalizados, disidentes...- son individuos ex-céntricos que se encuentran en una situación de desajuste. Posición que puede transformarse de muchas maneras, según sea la situación inicial que determinó o provocó el desajuste y la voluntad o posibilidades de ambas partes de transformarla.

Así nos encontraremos con la reversión a un estadio anterior, permanencia, endurecimiento o empeoramiento del mismo. En este último caso, tendremos al individuo o grupo en un estado de marginalización más claro y definido que puede llegar incluso a transformarse en otra situación más definitiva, la exclusión.

Yo he tomado en mi clasificación de marginalidad en la Edad Media dos grandes valores de referencia, los de ecumenidad y particularismos ${ }^{21}$, el primero con sentido de la ecumenidad cristiana, el segundo con el de formas políticas menores que la substituyen al final de la Edad Media.

Es interesante una frase de Jacques de Vitry ${ }^{22}$ porque plantea la interacción entre unidad y particularismos. De manera evidente, la unidad que propone el autor es anacrónica puesto que habla del imperio romano que él ve dividido y enfrentado: «los habitantes de Francia guerreaban contra los ingleses; en España, los sarracenos oprimían a los fieles más allá de todo límite; el reino de Sicilia estaba destrozado por disensiones y combates; todas las regiones de Occidente, golpeadas por diferentes tribulaciones se veían afligidas por el juicio de la venganza divina». Cualquiera que sea la caracterización de esa unidad -aun erróneamente calificada- es claro que aparece ante la observación del relator una unidad primera que se disgrega en unidades menores, además de ser atacada por exogrupos.

He meditado acerca de la oportunidad de modificar esos valores de referencia pero creo que en una sucesión cronológica se afirman, como identidades, la «Christianitas" por un lado y los particularismos por otro. Podríamos haber dicho nacionalidades pero me retienen de hacerlo los ámbitos que han forjado lentamente el concepto y la realidad de nacionalidad tal como lo entendemos contemporáneamente. Italia o Alemania medievales mantuvieron más prolongadamente una división en particularismos que no corresponden al criterio de nación. Aunque digamos que hay sucesión cronológica en verdad hay un ámbito temporal en que se superponen ambos valores.

Podríamos tomar nuevamente como ejemplo la Historia de las cruzadas de Jacques de Vitry. En ese texto podemos señalar el valor de ecumenidad, en las dos intentadas ecumenidades que se enfrentan, Cristiandad e Islam. En esa oposición, los musulmanes son calificados con los duros términos que se han acuñado como formas reiteradas, "perros inmundos" ${ }^{23}$. De ordinario, la imagen que se ofrece del musulmán es un lugar común. El enfrentamiento confesional entre cristianos y musulmanes se agudiza en el choque bélico, se expresan generalizaciones, conceptos

\footnotetext{
21 Ver Marginalidad en la Edad Media, ed. cit., p. 11 y ss. Modos de marginalidad en la Edad Media: extranjoria, pobreza, enformedad.

22 Jacques de VITRY, Histoire des rroisados, collection des mémoires relatifs a l'histoire de France par M. Guizot, 22, París, 1985, 1. II, p. 285.

23 Id., 1. I, p. 250.
} 
que establecen una clara polaridad, los cristianos concentran el elemento positivo y negativos son, en cambio, los musulmanes, tanto en lo físico como en lo espiritual.

Dentro del grupo de cruzados que se baten en Tierra Santa y que teóricamente representan a la ecumenidad cristiana, se dibujan ya los particularismos políticos. Es interesante ver cómo el cronista señala las características que él supone individualizan a cada una de las nacionalidades. Verdaderas o no, esas características implican el planteo de identidades nacionales diferentes. Habla de la Tierra Santa poblada por gentes de toda las razas, de todas las naciones, allí se encuentran los venecianos, los genoveses, los pisanos, además de gentes de Francia y de Alemania. Unos son fuertes y capaces en el mar, los otros bravos en tierra, aptos para combatir como caballeros.

«Los hombres de Italia, más graves y más serenos, sabios y prudentes, sobrios tanto respecto de la bebida como de la comida. Ornados y cuidados en su lenguaje, llenos de circunspección en los consejos, activos y celosos en el cuidado de sus asuntos públicos, tesoneros y sabios en tomar precauciones para el futuro, rehusando siempre someterse a los otros, defendiendo su libertad más que toda otra cosa, fijando en sus comunidades sus derechos y sus instituciones y observándolos fielmente bajo la autoridad de un capitán que eligen de entre ellos. Son absolutamente necesarios en Tierra Santa no sólo en los combates sino además para el servicio del mar y para el transporte de mercaderías, peregrinos y víveres. Y, como son moderados en lo relativo a la bebida y a los alimentos, viven en las regiones de Oriente más largamente que los demás pueblos occidentales».

Compara inmediatamente a estos prudentes italianos tan bien insertados en Tierra Santa con los alemanes, los franceses, los bretones, los ingleses y los demás europeos.

Todos estos son «menos graves y más impetuosos, menos circunspectos en la acción, se abandonan en mayor medida a los excesos de la bebida y de los alimentos, más pródigos en sus gastos, menos prudentes en su lenguaje, «menos previsores en los consejos, devotos a la Iglesia, más generosos en sus limosnas y en otras obras de misericordia, más valientes en los combates, son infinitamente útiles en la defensa de la Tierra Santa..." ${ }^{24}$.

Aquellos descendientes de europeos nacidos en Oriente se llaman poulains, término cuya etimología es obscura. Tal vez alude a pullus o pollo, tal vez porque en relación con los sitios son los más jóvenes, los recién llegados. O porque la mayor parte de sus madres proceden de Puglia. Esos poulains también son caracterizados, dibujados con una evidente actitud de rechazo. Son muelles, afeminados, prefieren más los baños que las armas, lujuriosos, cobardes y pusilánimes, aparecen con vestimentas excesivamente adornadas ${ }^{25}$.

El desprecio con que cubre el cronista a los criollos de Tierra Santa indudablemente está en relación con una posible debilidad confesional y con una sospechada simbiosis con los musulmanes. Ese mismo desprecio se expresa respecto de los

24 Id., 1. I, p. 126.

25 Id., 1. I, p. 137. 
surianos o habitantes de Sur, a pesar de ser cristianos.

Siempre sometidos -o esclavos o tributarios- «inútiles para la guerra tanto como las mujeres». "Esos hombres son en su mayor parte sin fe, llenos de duplicidad en relación a los griegos, astutos como zorros, mentirosos e inconstantes, ambiciosos de fortuna, traidores, fácilmente corrompibles por medio de presentes, con un lenguaje en la boca y otros sentimientos en el corazón, no encontrando ningún mal en el hurto y en la rapiña. Convertidos en espías a bajo precio, denuncian los secretos de los cristianos a los sarracenos, enmedio de los cuales se han criado y cuya lengua emplean preferentemente a toda otra. Participan de la perversidad de éstos casi totalmente, pues se han mezclado con ellos y han aprendido a practicar sus costumbres" ${ }^{26}$. Decimos que Jacques de Vitry desprecia y cubre de oprobio a los poulains. Según el autor son borrachos, bufones, mimos, histriones, malvados que dejaron Occidente y que llegaron a Oriente con sus vicios. Allí engañan a los peregrinos, se dedican a los juegos de azar, aceptan a las mujeres de mala vida ${ }^{27}$.

Los vicios que el cronista les atribuye sin duda están determinados por su relación con los musulmanes, una manera de contaminación.

Pero además de hablar de estas dos grandes entidades podríamos relativizar nuestro análisis y hacer referencia a entidades o grupos menores a los señalados. Es decir, que el individuo o grupo que se siente marginado o que se margina lo hace con referencia a un núcleo, a un ámbito, a un grupo de menor extensión.

En la actualidad, estoy trabajando sobre individuos que tienen una posición no apical dentro de la estructura familiar de la rica burguesía florentina de los siglos XIV y XV ${ }^{28}$. Me he interesado por la jerarquización que se daba en la familia. Había un jefe que regía relaciones domésticas, económicas y políticas del núcleo, que determinaba de qué manera ese grupo había de ponerse en contacto con un adentro y un afuera. En torno a ese jefe se encontraban los demás miembros entre los que se establecía una jerarquía evidente.

Había diversos motivos que determinaban la posición secundaria. Uno de ellos era el sexo. Otro podía ser el nacimiento ilegal. Nos hemos ocupado de cómo estas minusvalías se daban en la mujer sola. En aquélla en la cual a la debilidad de su sexo se unía la carencia que significaba la ausencia de apoyo de un núcleo social.

Pero también - para no dejar el ámbito de la familia- podríamos plantear el caso de quienes participan sin ser miembros de ella, los servidores. Me interesa particularmente el tipo del servidor-confidente. Es como si ese personaje, a quien el ámbito familiar reserva un lugar determinado, abandonara - por voluntad de su

26 Id., 1. I, p. 141-2.

27 Id., 1. I, Pp. 168-170.

28 En preparación, Familia y sociedad (Italia del centro y del norte Siglos XIII-XV). Además: Le femme seule (Italie du centre et du nord. XIII-XVe siècles), «Razo, Cahiers du Centre d'Etudes médiévales de Nice», Université de Nice. La 'tornata' de la mujer viuda, Homenaje al prof. Dr. Ferrán Valls Taberner, Universidad de Málaga, Facultad de Derecho, Departamento de Derecho Privado especial. La viuda tutora, Homenaje al prof. Dr. Emilio Sáez, Madrid. 
señor-su zona. Es atraído por su ama hasta su propia zona privilegiada, participa de su vida, de sus secretos, de su confianza. A cambio de este ascenso, del gozo de esta situación que no le corresponde, que no le es propia, ha de sacrificar mucho de sí. Además, se instala precariamente en esa zona privilegiada, tan extensamente como sea del deseo de su amo. Pensamos en la Brangania de Tristán e Isolda. Se sacrifica por su señora la noche de bodas y -poseedora de su secreto- es librada a la muerte por temor de alguna indiscreta confesión. Se indigna la reina ante el asesinato encomendado e increpa a quienes había encargado de cumplirlo: "vous m'avez tué mon amie" ". Descubierto el engaño, recibe a Brangania con grandes muestras de afecto: "Yo seré tu fiel amiga en adelante; perdóname Brangania y continúa siendo mi amiga" ". Promesas y nombre de amistad que implican la voluntad del señor que concede según circunstancias, humor y talante.

Lo que hemos querido destacar en este episodio es la suerte peculiar e inestable que puede acompañar a quienes salen temporalmente de una situación marginal para ubicarse en otra más importante, pero en que la circunstancia y el azar pesan en gran medida.

Traigo ahora a colación otros ejemplos que pueden ilustrar con datos de la historia medieval los presupuestos aquí indicados.

En primer lugar, aportaré un texto que nos permita establecer una de las relaciones posibles entre núcleo e individuo.

En segundo lugar reflexionaré sobre la identidad del disidente. Podemos asomarnos en este ejemplo a la diferenciación del disidente encubierto y del disidente evidente.

También sería interesante ver cómo se da la incorporación de los alógenos; podría tratarse del grupo negro o de conversos que - procedentes de otra confesiónquieren constituir una unidad con el grupo mayor al que acceden ${ }^{31}$.

Podemos ver también si esa voluntad está determinada por un real convencimiento o por circunstanciales conveniencias.

El análisis de estos ejemplos -como de otros muchos- nos lleva a plantearnos el problema del testimonio. ¿Cuándo el testimonio es directo y consciente cuya intención hemos de señalar según sea el emisor; cuándo estamos en presencia de un testimonio indirecto, cuya naturaleza hemos de desentrañar con cuidado? Nos preguntamos en qué medida los que sufren marginalidad pueden expresar su peculiaridad, pueden darla a conocer, publicitarla. Pensamos en los mudos y en los enmudecidos, en los que no tienen voz social. Por un lado, no todos logran la conciencia necesaria que les permita formular su pensamiento y quienes la poseen no siempre pueden hacer oir esa voz.

29 Tristan. La merveilleuse bistoire de Tristan et Iseut, rostituée par André Mary. Préface de Denis de Rougemont, Gallimard, Paris, 1973, p. 108.

30 Id., p. 109.

31 Eloy BENITO RUANO, art. cit., PP. 35 y ss. Negritud. Respecto de otro ámbito confesional, Bernard LEWIS, Razza e colore nell'lslam, Milano, Longanesi \& C., 1975. 
Euripides en Las fenicias "imagina un diálogo entre Polínices y Yocasta.

Ésta dice: ¿Qué es estar privado de patria? ¿Una gran desgracia? Pol. La mayor; la realidad supera a las palabras.

Yoc. ¿Cómo es? ¿Qué se hace insoportable para los desterrados? Pol. Algo de importancia suma, no tener libertad de hablar. Yoc. Propio de esclavo es lo que dices, no decir lo que se piensa.

Lucano se queja "del acallamiento del oráculo de Delfos durante el reinado de Nerón.

«... de ningún don mayor otorgado por los dioses carece nuestro tiempo, que es el de la voz, ahora silente, de la sede délfica, una vez que los reyes temieron el futuro y a los dioses vedaron hablar...»

En ocasiones, quien defiende, alienta o propone modificaciones contemporáneas insufla vida y presta palabras a individuos que - en el pasado- lucharon por causas análogas, por nuevos rumbos en la sociedad, por transformaciones similares.

Machiavelli pone en boca de uno de los ciompi que -presuntamente- reflexiona sobre la justicia de su causa y de su acción, estas palabras: "No os asuste aquella antigüedad de la sangre que nos reprochan; porque todos los hombres habiendo tenido un mismo principio son igualmente antiguos y han sido hecho iguales por la naturaleza. Desnudáos, dejadnos desnudos a todos, veréis que somos semejantes; si nos revestís con sus vestimentas y a ellos con las nuestras, sin duda nosotros pareceremos nobles y ellos innobles; porque sólo la pobreza y la riqueza nos diferencian...». En este caso, quien supuestamente habla es tomado como vehículo para expresar problemas y aspiraciones que corresponden al momento del escritor ${ }^{34}$.

A veces, hay artilugios para hacerse oir: generalmente el disfraz, la fiesta regocijada y en apariencia frívola permitía decir una verdad que, de ordinario, era difícil de expresar. El enmascarado, el loco-tonto, el «inocente», el bufón... se permitían decir verdades que llegaban con apariencia de broma o de palabra ingenua...

Con apariencia, decimos. Las cantigas de escarnio galaico-portuguesas utilizaban para su juego crítico "palabras encubiertas que tenían dos acepciones». Las cantigas de maldecir habían decidido adoptar el aspecto "de un género de cómica sinceridad" ${ }^{35}$.

A veces, en efecto, el anonimato permite una clara expresión de propósitos. En las Coplas del Provincial se declara:

\footnotetext{
32 Luis GIL, Censura en el mundo antiguo, Madrid, Alianza editorial, 1985, p. 49.

33 Id., p. 130.

34 Niccold MACHIAVELl, Istorie fiorentine, Milano, Feltrinelli editore, 1962, 1. terzo, xIII, p. 237.

35 Nilda GUGLIELMI, Los elementos satíricos en las Coplas de la panadera, "Filología», XIV, 1970-1, Fac. de Filosofía y Letras, Universidad de Buenos Aires, p. 64.
} 
El Provincial es llegado

a aquesta corte real, de nuevos motes cargado, ganoso de decir mal.

Intenta zaherir con una verdad imposible de exhibir a cara descubierta:

y en estos dichos se atreve

(y si no, cúlpenlo a él)

si de diez veces las nueve

no diere en mitad del fiel. ${ }^{16}$

Federico II Hohenstaufen $(+1250)$ fundó una ciudad-campamento en Lombardía para combatir a las rebeldes ciudades italianas. Los parmenses lograron conquistarla. En ella perdió -además de la oportunidad estratégica que representaba- su tesoro. En él se encontraba la corona imperial que, según dice Salimbene de Adam -el cronista franciscano del siglo XIII-, era grande "pero mayor por su dignidad y riqueza que como ornamento de la cabeza» ${ }^{37}$.

Federico -en su exótica corte- tenía un bufón. Burlonamente el emperador tocó un día su joroba y le preguntó: "¿Dónde habéis perdido la llave de este escritorio?». A lo que respondió el bufón: «En Vitoria, señor».

El poeta cortesano que ha de alabar y condescender con sus nobles señores - no siempre puede replicar tan directa y frontalmente como el bufón- se venga sin embargo en el anonimato mediante las coplas agresivas que deshonran y desacralizan.

Recordemos las Coplas de la panadera en que ese fingido personaje vulgar y plebeyo ridiculiza la conducta de los grandes señores castellanos en la batalla de Olmedo (19 de mayo de 1445). La poesía popular italiana criticó y zahirió. En los Proverbia que dicuntur super naturam feminarum (s. XIII?) ${ }^{38}$ el poeta se presenta:

«Soy un noble observador y un fino poeta

por amor no se conmueve ni mi mente ni mi corazón

por odio a ninguno injurio ni alabo por amor

no tampoco dejo de decir la verdad por temor.

Cualquier cosa que el otro haga, ya sea hablar o callar,

yo diré siempre lo que me dé placer».

Libre se siente pues quien puede decir la verdad.

Lo importante es que esa $s u$ verdad no sea en realidad crítica mezquina, no quede en el juego cómico y regocijado, no sea desahogo de rencorosa frustración sino que canalice corrientes de opinión. Lo importante es que su voz pueda entenderse

36 Id., p. 67.

37 Salimbene de Adam, Cronica. Nuova edizione critica a cura di Giuseppe Scalia, 2 vols, Scrittori d'Italia, Bari, Laterza, 1966, vol. I, p. 293. A. 1247.

38 Francesco DE SANCTIS, Storia della letteratura italiana dai primi secoli agli albori del Trecento, Milano, Ulrico Hoepli, 1950, p. 186 y ss. 
como una voz múltiple y plural. Que mudos y enmudecidos puedan hablar por él.

Vayamos ahora a los ejemplos anunciados. El primero trata de la relación entre núcleo $e$ individuo.

\section{NÚCLEO E INDIVIDUO}

Para ello analizamos las palabras que la figura alegórica de la Filosofía pronuncia al acudir ante los lamentos de Boecio (s. VI).

Escribe el autor de La consolación de la filosofía: "Cuando hube gritado esto con angustia sin fin, ella -es decir la Filosofía- con rostro sereno y no turbada en absoluto por mis lamentos, dijo: Cuando te vi apesadumbrado y lloroso, inmediatamente comprendí que eras infeliz y exiliado. Tú, sin embargo, no has sido expulsado de tu patria, sino te has extraviado o, si prefieres creerte expulsado, más bien tú te has expulsado de ti mismo..." '. En estas frases aparecen los dos elementos que hemos mencionado, por un lado el ámbito receptor, por otro, el individuo que en él reside y a él debe integrarse. Señala la Filosofía cómo la integración ha de darse de manera voluntaria, en adhesión cordial.

«En efecto, para quien está dentro de la cinta de sus fortificaciones -se refiere a la ciudad- no hay peligro que merezca ser exiliado; en cambio quien ha cesado de querer habitar allí, cesa al mismo tiempo de merecer tal residencia» ${ }^{2}$.

En este caso, el apartamiento evidente, la prisión que la sociedad hace sufrir a Boecio estaba ya predeterminada, decidida por el mismo personaje castigado, él la había dispuesto. Destaquemos que la Filosofía habla reiteradamente de exilio cuando, a los ojos de todos, se trataría de prisión.

Ese aislamiento en realidad significa apartamiento, un apartamiento no tanto material, de ámbito físico, cuanto una separación de adhesión, una negativa de consenso.

En este caso no aparece el juego flexible, a uno solo de los participantes corresponden actitudes, al individuo. Esa sociedad en la que se inserta, aparece como un cuerpo perfecto y acabado, inmodificable y sin mácula que hay que aceptar en su totalidad.

Tampoco el prisionero-exiliado considera culpa alguna en esa estructura, sólo piensa en la tergiversación que los hombres han introducido en esos valores.

Pero esta declaración de adhesión no ciega a la Filosofía que encuentra la razón del apartamiento en el propio Boecio, quien se ha separado de sí mismo, de lo que debía constituir su identidad. Es el individuo quien ha roto la armonía sobre la que supuestamente se basaba esa sociedad.

\footnotetext{
1 Boezio, La consolazione della filosofia, Rizzoli, p. 105.

2 Id., pp. 105-7.
} 
DISIDENTES.- Podríamos hablar del disidente evidente y explícito, con conciencia de serlo y de aquél en que la protesta se expresa a veces sin ser totalmente identificada como tal por quien la actúa. Ejemplos del primer caso: podría tratarse de guías o jefes religiosos, ya heréticos como Dolcino de Novara, ya ortodoxos como San Francisco. En ambas circunstancias pensamos que son disidentes que quieren volver a una situación anterior, que quieren reinstaurar un ordo que consideran degradado. Se sitúan al margen para, desde allí, lanzar su mensaje, no participan de esa sociedad pero no la ignoran. En general, estos personajes parecen revolucionarios pero, en verdad, defienden la permanencia de un viejo mundo que creen perdido o deformado. Destacamos en este caso la posible relación marginal-marginalizado. Como dice Troeltsch ', «la afinidad electiva de todos los estratos inferiores y rebeldes».

A veces el disidente no tiene conciencia de su protesta, en ocasiones la tiene muy neta pero hay que descubrirla tras enmascaramientos muy sutiles. Desearía dar dos ejemplos de disidentes que lanzan su protesta de manera diferente. Uno lo hace en forma encubierta, el otro de forma directa.

Me refiero al anónimo autor de las Coplas de la panadera ${ }^{2}$ por un lado, quien se enmascara para lanzar rudos ataques contra un grupo social del que participa-según suponemos- de manera marginal.

Tomamos además otro ejemplo, la poesía de Rutebeuf ${ }^{3}$.

Nos preguntamos en ambos casos por la posible intención, el alcance de esa protesta, su afán de destrucción, su propuesta constructiva...

A la vez, la sociedad expresa su actitud respecto del disociado de diversas maneras.

Puede condenar su conducta o alejarlo emitiendo opiniones que, aunque vertidas con una apariencia neutra, encubren juicios negativos. Pero también un grupo puede enjuiciar a los que no pertenecen a él por diferenciarse en conducta, características diversas, actitudes emitiendo juicios más expresivos.

Pero en los casos que nos proponemos queremos examinar la contraparte. El singular, el apartado, el disociado, puede enjuiciar al grupo de que se aparta expresando el juicio que le merece de manera emocional: con ira, agresividad, ironía...

Puesto que el lenguaje es parte del comportamiento, importa enormemente considerar cuál es el lenguaje en estos casos ya que se trata de una forma de comunicación o conversación entre los dos grupos o el grupo y el individuo, conversación de alto valor expresivo y gestual. En este caso interesa examinar la emisión y el emisor de esos mensajes que implican la comunicación entre los grupos

\footnotetext{
1949.

1 Ernst TROELTSCH, Le dottrine sociali delle chiese e dei gruppi cristiani, Firenze, "La Nuova Italia» editrice,

2 Ver ut supra, ed. cit.

3 Ver más adelante.
} 
y la recepción. Esta recepción no significa de manera alguna aceptación. Por tanto, importa volverse hacia unos y otros -emisores y receptores- y también hacia la transmisión expresada en el signo, que puede darse en palabras aunque no siempre se requieran.

El signo-lenguaje es importante para nosotros en sus diferentes dimensiones. En sus aspectos descriptivo, cognoscitivo y emotivo. Se describe o señala una situación que presenta aparentemente caracteres de normalidad o coincidencia con la normativa, cuya disonancia se expresa en el desajuste de situaciones aparentes y reales o en el desajuste a veces subrayado por la introducción de un nivel de lenguaje discordante con la situación presentada.

La sátira «es una de las formas literarias -según nos dice Kenneth R. Scholberg en Sátira e invectiva en la España medieval ${ }^{4}$ - que con mayor veracidad refleja, a veces, los problemas, las preocupaciones y los conceptos morales de una época». No utiliza lenguaje emotivo. «El satírico -dice Middleton Murray-' tiene que suprimir y ocultar su emoción..... Por supuesto, la sátira puede revestir diversas formas y expresarse en diversos niveles y en algunas de sus expresiones más bajas puede utilizar lenguaje soez y escatológico no a manera de invectiva o ataque directo sino como medio de desacralizar ambientes, situaciones o personajes que se quieren ridiculizar.

Cercana a la sátira se encuentra la invectiva -algunos autores hablan de invectiva -sátira- la forma más directa de la sátira. Interesa para nuestro análisis subrayar lo que dice Kenneth Scholberg ${ }^{6}:$ "La distinción a veces es dificilísima de hacer». Cita las palabras de Murray quien distingue entre sátira e invectiva de la siguiente manera: «La sátira no es cuestión de resentimiento personal, sino de condenación impersonal. En parte por obra de la tradición clásica, la invectiva y la verdadera sátira suelen mezclarse y confundirse bajo un nombre común; pero habría que distinguir entre una y otra. La verdadera sátira implica la condenación de una sociedad por referencia a un ideal; difiere de la invectiva en que no es un ataque enderezado por un individuo a otro individuo" '. Sobre el lenguaje de la sátira, Highet dice ${ }^{8}$ : «La mayor parte de las obras satíricas contienen palabras triviales y cómicas; casi todas las obras satíricas contienen palabras coloquiales anti-literarias». En general, suciedad, trivialidad, vulgaridad sirven para describir y por tanto como elementos de oposición -ambientes, personajes o situaciones teóricamente dignas, elevadas y nobles. Lefebvre ${ }^{9}$ menciona este procedimiento como "de dévaluation par le contraste comique».

Emplear palabras soeces para aludir a alguien que se considera enemigo o desagradable, aunque tenga consenso de nobleza o prestigio, es querer imponer una

\footnotetext{
9 Joßll LEFEBVRE, Les fols et la folie. Étude sur les genres du comique et la création littéraire en Allemagne pendant la Renaissance, Paris, Librairie C. Klinscksieck, 1968, p. 41.
} 18.

4 Biblioteca Románica Hispánica, Madrid, Editorial Gredos, S.A., 1971, p. 9.

'Cit. por Scholberg, ob. cit., p. 10.

6 Id., p. 11.

7 Cit. por Scholberg, p. 11.

8 Gilbert HIGHET, The anatomy of the satire, Princeton, New Jersey, Princeton University Press, 1962, p. 
realidad distinta a la verdadera. Esa realidad creada trata de lograrse por medio del realismo verbal. La fuerza del realismo verbal es tal que de ordinario se pide la retractación para deshacer lo creado. «Esa ingenuidad de confundir el lenguaje con la realidad sería difícil de comprender si no tuviéramos presente el papel importante que desempeña en el pensamiento humano la magia verbal " $"$.

En todo ataque o crítica es importante acuñar expresiones en que la situación, persona o cosa criticada o atacada vaya acompañada de términos desacralizadores, de tal manera que - aunque inconscientemente- se crean símbolos semánticos que canalizan las fobias ". La sátira es una de las formas literarias en que puede expresarse el rechazo de la sociedad al marginal o la condena del marginal a los valores de la sociedad que enfrenta.

He elegido para ejemplificar esto -según ya he dicho-las Coplas de la panadera. Y la poesía de Rutebeuf. En el primer caso nos encontramos con un marginal que expresa sus críticas a la sociedad que le rodea. Al estudiarlas ${ }^{12}$, yo he supuesto que la panadera representa al autor de esas coplas irreverentes que satirizan a la nobleza, indicando la carencia de virtudes propias de su grupo.

Yo he propuesto la tesis de que el autor de las Coplas de la panadera es un poeta cortesano de la corte de Juan II. Se han supuesto algunos nombres ciertos como el de Juan de Mena. He pasado revista a las obras del autor del Laberinto de fortuna y no hay motivos para suponer que haya escrito una composición tan agresiva como las Coplas, que expresa situaciones escatológicas en lenguaje soez.

Otras posibles autorías señaladas -Enrique de Villena, Fernán Pérez de Guzmán, el marqués de Santillana- no encuentran mayor fundamento que la de Juan de Mena.

Yo he insinuado en mi trabajo que el autor -sea Juan de Mena o no- puede ser un literato cortesano que haya pertenecido a la corte en función de su actividad literaria. Pero recordemos que la corte literaria de Juan II comprendía grandes nombres nobles que -como el marqués de Santillana- además de pertenecer al círculo literario formaban parte de un grupo social noble y de los colaboradores políticos del monarca.

Los grupos burgueses que ejercían actividades de carácter intelectual eran criticados. Dentro de las críticas posibles podemos contar las que surgían de otros grupos burgueses o de grupos nobles o eclesiásticos.

Por supuesto, se entiende la razón de la crítica a legistas, abogados u hombres de justicia. Se criticó su avidez de dinero, su venalidad constante. Se temió la preparación técnica que los situó cerca de los monarcas como consejeros, que les permitió constituirse en una especie de nueva nobleza que reemplazó a la vieja en el ejercicio del poder.

10 Gordon W. AllPORT, La naturaleza del prejuicio, Buenos Aires, Eudeba, 1961, p. 211.

11 Id., pp. 210-2.

12 En lo que sigue, resumo lo expuesto en el artículo citado, no creo necesario mencionar páginas. 
Diferente es la situación del intelectual burgués que elige su actividad como vocación y como ocupación ". En este caso, pensamos que es particular la situación de este intelectual burgués, incorporado a la vida cortesana entendida como cenáculo literario pero no aceptado en esa vida cortesana como miembro del grupo noble. Aun si lo equiparamos en su dimensión intelectual a cualquiera de los nobles literatos, debemos entender que no puede tener el mismo peso su actividad ejercida en la corte. El prestigio del linaje importaría enormemente para la consideración de la labor intelectual dada en un círculo áulico.

He dicho en mi artículo que el autor desconocido de las Coplas es «miembro de una clase social que convive con otra a la cual no puede integrarse plenamente. Su situación respecto de ella es periférica. Era un marginal, tanto en relación a su clase burguesa que veía con desconfianza su convivencia con la nobleza y sobrevaloraba sus posibilidades de ascenso y, por tanto, de abandonar su clase, como respecto de la nobleza con la que compartía ciertas condiciones culturales pero no sus pautas de clase».

El literato cortesano, miembro de la clase burguesa, podía no presentar estabilidad y armonía ante las expectativas que se le imponían. O podía presentar estabilidad y armonía parcial - temporal o circunstancial- expresando de alguna manera su desarmonía. Eso se logra actuando en diversos contextos y por tanto desempeñando diferentes roles. "Estos tipos de personas parecen recobrar en su contexto lo que pierden en otro. Explotando sus posibilidades de hacerse ver en un rol, compensan las frustraciones que sufren en otro" ${ }^{14}$. O sea, la falta de unificación que podía presentar el poeta cortesano, miembro de una clase obligado a actuar en un contexto que no le era propio, podía resolverse eventualmente en acciones; en el caso que nos ocupa se convertiría en denigrador de un ordo que, de ordinario y actuando de acuerdo con las expectativas que caían sobre él, recibiría su aprobación y loa.

Lo que decimos nos lleva a suponer, pues, que el autor de las Coplas, poeta cortesano, intelectual burgués, no enjuicia a ciertos individuos, pertenecientes a un grupo determinado, sino que realiza la crítica del status mismo.

He estudiado en el artículo citado el modo de ejercer la crítica en las Coplas. Se trae a colación el comportamiento cobarde, es decir, que no coincide con las premisas del status - de los personajes nobles que intervinieron en la batalla de Olmedo (1445). La narración no-satírica de tal acontecimiento hubiera requerido un estilo noble, en situaciones y lenguaje. Se recurre a todo lo contrario: se utiliza el anticlímax, el contraste; se oponen lo grave y lo ridículo. La personalidad de cualquiera de los nobles mencionados era aparentemente noble y elevada. Las Coplas echan mano del artificio de presentar dignamente -en ademán y vestiduras-a cada uno de los señores en los primeros versos y luego, contrapuesta, aparece la situación inesperada y ridícula.

152.

13 Manuel García-Pelayo, El reino de Dios, arquetipo político, Madrid, Revista de Occidente, 1959, p.

14 H. GERTH y C. WRIGHT MILlS, Carácter y estructura social, Buenos Aires, Paidós, 1963, p. 115. 
RUTEBEUF.- Podemos presentar otro ejemplo de intelectual burgués que ejerce la sátira respecto de su sociedad, un poeta de quien conocemos la vida y obra, Rutebeuf. No podemos precisar la fecha de su nacimiento pero sabemos que desarrolló su obra en el siglo XIII y murió hacia fines de siglo, en fecha también desconocida. La datación de La Mort Rutebeuf, su última composición, también es incierta. Se han aventurado los años de 1270, 1277, 1285.

No fue poeta cortesano de la misma manera que lo fue Juan de Mena, si éste fuera el autor de las Coplas. Tuvo vida de juglar y «como los juglares, sus camaradas, Rutebeuf vivió de los recursos que le procuraba la protección de los ricos»'.

158. Monseignor qui est filz de roi

Mon dit et ma complainte envoi,

Qu'il m'est mestiers

Qu'il m'a aidié volentiers:

Ce est li bons quens de Poitiers

163. Et de Toulouse ${ }^{2}$.

Así escribe el poeta en la Complainte Rutebeuf. Ya muerto su benefactor, en la Complainte du Comte de Poitiers dice:

76. Ce qu'il faisoit, faisoit de lui

Et donoit si cortoisement

86. Mais se por bontei ne por don

A prudons le regne celestre,

Li cuens Aufons i doit bien estre ${ }^{3}$

Pero él conoció tanto la inestabilidad de las protecciones principescas como la falta de reconocimiento de su talento por parte de sus contemporáneos. No siempre fue feliz en lograr éxito en círculos burgueses a los que quiso agradar para sobrevivir. «Se encuentran en él acentos vigorosos para denunciar las taras de una sociedad que lo aplasta" ${ }^{4}$.

Se ha tratado de diferenciar en su obra la poesía polémica de la poesía personal. Pero en ésta suponemos que no sólo narra las vicisitudes de su existencia sino que eleva a esa vida a condición de arquetipo. En las poesías personales «pone de relieve

1 Arié SERPER, Rutebeuf poète satirique, Paris, Éditions Klincksiek, 1969, p. 46.

2 La complainte Rutebeuf, 158, «A Monseñor que es hijo de rey / envío mi composición y mi queja / puesto que estoy en la miseria / El me ha ayudado de muy buena gana / El es el buen conde de Poitiers. /163. Y de Toulouse».

${ }^{3}$ Cit. por SERPER, ob. cit., pp. 46-7. «Lo que él hacía lo hacía por su propia iniciativa/ Y daba con mucha cortesía /.../ Pero si por bondad o por generosidad/ se logra el reino celeste/ el conde Alfonso allí bien debe estarn.

4 SERPER, ob. cit., p. 49. 
sus intenciones satíricas respecto de una sociedad que toleraba que los juglares viviesen como pobres mendigos..."'?

En su poema La pauvreté de Rutebeuf, dice:

Je ne sais par ou je commence

Tant ai de matière abondance

Pour parler de ma pauvreté

Pour Die vous prie, franc roi de France,

Que me donniez quelque chevance,

Si ferez trop grand'charité.

Du bien d'autrui j'ai subsisté

Que l'on m'a creü et prêté:

Or me faut chacun de créance,

Qu'on me sait pauvre et endetté;

Où toute avais mon atendance ${ }^{6}$.

Su idea de mendicidad, la necesidad de un protector aparecen expresadas casi con las mismas palabras en La mort Rutebeuf:

$J$ 'ai toujours engraissé ma panse

Du bien d'autrui, de sa substance'

En La grièche d'biver juega con las palabras pauvre-pauvreté. Emplea términos vulgares y groseros como hemos visto en los párrafos anteriores. Este vocabulario encubre una clara agresividad contra su sociedad y actúa como recurso cómico. Mezcla de jocundidad, tristeza y agresión, se burla de su miseria de la que, en suma, responsabiliza a su sociedad ${ }^{8}$.

Contre le temps qu'arbre défeuille

Qu'il ne demeure en branche feuille

Qui n'aille à terre

Pour pauvreté qui moi atterre,

Qui de toutes parts me meut guerre

Contre l'hiver,

Dont moult me sont changés les vers,

Mon dit commence trop divers

De pauvre histoire.

5 Id., p. 48.

6 RUTEBEUf, ed. G. Lafeuille, p. 170. «Yo no sé por dónde comenzar / tan abundante es el tema/ para hablar de mi pobreza / Os ruego por Dios generoso rey de Francia/ que me déis alguna hacienda /De tal manera haréis una gran caridad / Yo he subsistido del bien de otros que me han creído y prestado/ Ahora me hace falta algún crédito/ pues saben que estoy pobre y endeudado / Vos habéis estado fuera del reino,/ en donde tenía toda mi esperanzaw.

7 Id., p. 172, vv. 19-20. «Siempre engordé mi panza/ con el bien de otro, con su riqueza».

8 Id., pp. 150 y ss. 
Pauvre sens et pauvre mémoire

M'a Dieu donnés, le roi de gloire,

Et pauvre rente,

Et frois au cul quand bise vente:

Le vent me vient, le vent m'évente

Et trop souvent

Plus d'une fois je sens le vent.

Aunque en otro pasaje dice:

En moi n'a ni venin ni fiel: '.

Inmediatamente agrega:

Il ne me reste rien sous ciel.

Tout va sa voie

Les enviaux que je savais

M'ont avoyé tout que j'avais

Et fourvoyé,

Et hors de voie dévoyé ${ }^{10}$.

Luego de haber declarado que los dados, es decir el juego, lo acechan, lo asaltan y lo matan, se duele de su suerte, del mundo todo:

Or suis entré en male trace;

Les trahisseurs de pute estrace

M'ont mis sans robe

Le siècle est si plein de lobe! ${ }^{11}$

Irónicamente alude a su afán por el juego que lo arrastra de manera violenta pero en última instancia la falta personalizada se vuelve contra la sociedad que no remedia carencias. En él se encuentra la dualidad: autoaborrecimientoaborrecimiento hacia los otros o hacia el exogrupo. Y se expresa en forma de compasión-agresión, en formas autopunitivas o exopunitivas ${ }^{12}$. Sentimientos que despierta su condición insuperable, se siente condenado a una vida de miseria:

La bourse est vide

Le jeu fait ce que l'on ne cuide; ${ }^{13}$

9 RUTEBeUf, ed. G. Lafeuille, p. 151, v. 40. «En mí no hay veneno ni hiel».

10 Id., p. 151, v. 41 y ss. «No me queda nada bajo el cielo / Todo sigue su camino/ Las apuestas que yo sé/ me han arrebatado todo lo que tenía / y me han engañado / y llevado fuera del caminon.

11 Id., p. 152, v. 61 y ss. «Ahora he entrado en mala senda/ los traidores de pura raza/me han dejado sin vestimenta/ El mundo está tan lleno de engaño!n.

12 ALLPORT, ob. cit., pp. 174 y ss.

13 RUTEBEUF, ed. G. Lafeuille, p. 156, vv. 57-8. «La bolsa está vacía/ el juego hace que uno no se preocupen. 
Pero aunque la bolsa no estuviera vacía, su situación no se modificaría demasiado, ya que:

Car deux tournois,

Trois parisis, cinq viennois

$\mathrm{Ne}$ peuvent pas faire un bourgeois

D'un misérable ${ }^{14}$.

Se ha discutido mucho si a estas poesías se les debe conceder solamente una dimensión personal y anecdótica. Yo pienso que, aunque en ellas se refleja una peripecia individual, no podemos dejar de lado la protesta de quien se enfrenta con afán racional con una sociedad y señala los fallos de la misma.

En su poema $L$ 'état $d u$ monde se muestra nostálgico de la perfección que tuvo el mundo y que ha perdido. No sabemos si esa nostalgia de un momento pasado puede aceptarse como la verdadera actitud de Rutebeuf o si en verdad él está preconizando el nacimiento de un nuevo estado de cosas:

Pour ce que le monde se change

Plus souvent que deniers à Change,

Rimer veux du monde divers.

Tôt fut été, or est hiver;

Bon fut, or est d'autre manière

Car nulle gent n'est plus manière

Du profit d'autrui rechercher,

Si son profit n'y croit trouver.

Chacun devient oiseau de proie:

Nul ne vit plus ni il ne proie.

Pour ce dirai l'état du monde

Qui de tous biens se vide et monde.

No sólo critica a las órdenes mendicantes sino a los demás religiosos y a los laicos:

Après ce que je vous devise

Me faut parler de sainte Eglise,

Que je vois de plusieurs chanoines,

Qui vivent du Dieu patrimoine,

Ils n'en doivent, selon le Livre,

Prendre que le suffisant vivre,

Et le remanant, humblement,

[Le]dussent-ils communément

A la pauvre gent partager;

Mais ils verront le coeur manquer

14 Id., p. 156, v. 66 y ss. «Pues dos torneses, /tres parisienses, cinco vieneses/ no pueden convertir en burgués / a un miserable». 
Au pauvre, de male aventure,

De grand'faim et de grand'froidure.

Quand chacun a chape fourrée

Et de deniers le grand' boursée,

Les pleins coffres, la pleine huche,

Ne lui chaut qui pour Dieu le huche,

$\mathrm{Ni}$ qui rien pour Dieu lui demande,

Car Avarice lui commande",

Se duele también de que hayan perecido las antiguas virtudes caballerescas.

Or m'en viens par chevalerie

Qui aujourd'hui est ébahie:

Je n'y vois Roland n'Olivier,

Tous sont noyés en un vivier;

Et bien peut-[on]voit et entendre

Qu'il n'y a plus nul Alexandre.

Leur métier défaut et décline;

Les plusieurs vivent de rapine.

$\cdots$

Je n'y vois ni prince ni roi

Qui de prendre fasse déroi,

Ni nul prélat de saint Eglise

Qui ne soit compain Convoitise

Ou au moins dame Simonie,

Car Charité est piéça morte!

Je n'y vois plus nul qui la porte,

Si n'est aucun par aventure

Qui retire à bonne nature;

Car trop est le monde changé,

Qui de tous biens est étrangé ${ }^{16}$.

15 Id., p. 125, vv. 1 y ss. «Puesto que el mundo cambia / más a menudo que el dinero en el cambio/ quiero cantar sobre el diverso mundo / Antes fue verano, ahora es invierno./ Bueno fue, ahora es de otra manera / pues nadie busca ya /el provecho de otro/ si su provecho no cree encontrar en ello/ Cada uno [persona] se transforma en ave de rapiña/ Nadie vive si no pilla / Por eso puede decirse del estado del mundo / que de todos los bienes se vacía y limpia». /.../ "Luego de lo que os describo / me es necesario hablar de la Santa Iglesia,/ pues veo que muchos canónigos,/ que viven del patrimonio de Dios,/ no deben, según el Libro,/ tomar sino lo necesario para vivir,/ y el resto, humildemente,/ lo deberían compartir con la pobre gente./ Pero ellos verán partirse el corazón/ del pobre, por la desdicha, / por el gran hambre y el gran frío/ cuando cada uno tiene una capa forrada / y una gran bolsa de dineros/ los cofres llenos, la hucha plena/ No vale que se los soliciten por Dios/ni que nada les pidan por Dios / pues Avaricia los gobierna».

16 Id., p. 127-8. «Ahora me ocuparé de caballería / que hoy ha desparecido / Ya no veré a Rolando ni a Oliveros / todos se han ahogado en el vivero/ y bien se puede ver y escuchar/ que ya no hay ningún Alejandro / su tarea falta y declina/ la mayoría viven de rapiña /.../ Yo no veo ni príncipe ni rey / que no aprehenda tranquilamente/ ni prelado de la Santa Iglesia / que no sea compañero de Codicia/ o por lo menos de Dama Simonía/.../ Pues Caridad ya ha muerto hace mucho!/ Yo no veo a nadie que la lleve / si no es alguien que por azar/ que logra por buena naturaleza / pues el mundo ha cambiado mucho / al punto que ha extrañado todos los bienes». 
Es interesante considerar el poema de Rutebeuf, Renart le Bestourné para entender la posición del poeta frente a la sociedad y a los grandes problemas de su época. Nos dará a conocer de qué manera la crítica cala hondo en las estructuras de la sociedad en que ese hombre está incluido.

Existe una anécdota que puede desviar la atención y hacer pensar que motivos personales y mínimos están en la base de la composición. Para conocer los detalles de la composición tomamos la opinión de los críticos literarios que largamente se han ocupado de la misma.

En 1261 Luis IX da orden de cerrar las puertas de la casa real, en particular durante las horas de la comida, a los juglares. Rutebeuf se sintió una vez más acosado ante esta decisión que prolongaba y aumentaba su ya frecuente miseria. Se vuelve contra Luis IX y contra los consejeros y privados, las órdenes mendicantes. Se vale para expresar su mensaje de los animales del Roman de Renart: el zorro, el lobo, el león... Cada uno de ellos representa a un personaje o a un grupo importante. Noble -el león- representaría al mismo Luis IX.

Los críticos que se han ocupado de la pieza «se han dedicado antes a lograr la identificación de los personajes que a estudiar la obra en su conjunto" " ${ }^{1}$. En nuestro caso, lo que nos importa fundamentalmente es su estilo e intención, que nos permitiría afirmar si el poeta se propone un ataque de más largo alcance, si su obra puede lograr términos abstractos o si se queda en la protesta personal y anecdótica. Como dice uno de sus críticos ${ }^{18}$ : «La concepción de la pieza, la cólera, el encarnizamiento que la animan, apuntan en primer término a las Ordenes mendicantes y a sus principales vicios, la hipocresía y la avaricia». La pieza tiene inmediatez cierta, pero también podemos rescatarla de ella para entender que el poeta protesta contra un orden que critica y condena.

Tenemos que pensar en la enemiga que separaba a Rutebeuf de las órdenes mendicantes y su origen y preguntarnos si Renart le Bestourné recibió el aliento de un enfrentamiento personal o si lo podemos considerar crítica de más alto alcance. Conocemos las circunstancias que provocaron el enfrentamiento. Después de 1229, los mendicantes se introducen en la enseñanza pública.

No corresponde que analicemos aquí por lo menudo el problema. Recordemos solamente la situación que se planteaba a fines del siglo XII cuando la escuela episcopal de Nôtre-Dame de París se transformó en Universidad. Existían problemas de jurisdicción, las muchas disputas que se planteaban entre los estudiantes podían ser resueltas por los tribunales laicos o los tribunales religiosos. Un desdichado accidente protagonizado por estudiantes en el carnaval de 1229, un intento de restablecimiento del orden por el preboste real y sus gentes, la muerte de algunos de los estudiantes, determinó una actitud sumamente enérgica de parte de los maestros y escolares. De no obtener justicia dentro de un plazo de seis meses, suspenderían las clases y abandonarían París. El Papa Gregorio IX en 1231, por la bula Parens

17 SERPER, ob. cit., p. 111.

18 Id. 
scientiarum, confirmó los privilegios de la Universidad otorgándole autonomía judicial.

Al retorno de la "dispersión», la situación se presentó complicada por la presencia en la Universidad de religiosos de las órdenes de Santo Domingo y de San Francisco.

La coherencia de los grupos universitarios demostrada en el episodio de 1229 se había roto. Esto apareció claro en 1253 cuando por el asesinato de otro estudiante se produjo otra cesación de clases. En ese momento los frailes no acompañaron la actitud de los demás maestros; se negaron a cesar en su enseñanza a menos de contar con la anuencia del Papa. Esto determinó el comienzo de una larga lucha entre los mendicantes y los demás maestros, lucha encabezada por Guillaume de SaintAmour -maestro regente de la Facultad de Teología- contra los frailes. Querella extensa y dura cuyo líder -Saint-Amour- es apoyado y acompañado por Rutebeuf.

Los mendicantes vieron debilitada su posición por la aparición de la obra de Gerardo de Borgo San Donnino, Liber introductorius ad Evangelium aeternum, impregnado por las ideas de Joaquín de Fiore. Los maestros atacaron a sus rivales señalando en la obra 31 errores. Los Papas se vieron envueltos en la disputa. Se produjeron bulas que apoyaron o atacaron a los frailes.

Guillaume de Saint-Amour anuncia el fin del mundo, a semejanza de la Introducción al Evangelio eterno. Pero, para el maestro parisino, el peligro que supone está en la aparición de falsos apóstoles -identificados con los mendicantes-, frailes que perturban el orden establecido por la Iglesia desde sus comienzos. Esos nuevos religiosos -según sus oponentes- no tienen derecho a la predicación ni a la mendicidad. Esta manera de vivir se considera impropia y se discute sobre la licitud de elegir la pobreza plena, la renuncia a toda propiedad. Guillaume de Saint-Amour afirma que ni Jesús ni los apóstoles practicaron la mendicidad ni la pobreza total. Se afirma que la pobreza puede ser un camino hacia la perfección, no se la puede considerar un acto de perfección en sí misma. Varios escritos de Saint-Amour desarrollan esta temática. El Tratado de los peligros de los últimos tiempos fue contestado inmediatamente por San Buenaventura, franciscano, ante los estudiantes de París. Se crea una comisión, se analiza la obra de Saint-Amour, es refutada por Santo Tomás de Aquino, se encuentran Saint-Amour y sus colaboradores por una parte y franciscanos y dominicos por la otra. Alejandro IV aprueba el ideal de vida de los franciscanos que «renunciando por Dios a todos los bienes del mundo y mendigando su subsistencia, imitan a Cristo pobre y abrazan la perfección evangélica, están pues en el camino de la salvación y la práctica de su Regla, conforme a las divinas enseñanzas de Cristo les corresponde la recompensa eterna" ${ }^{19}$.

Algunos de los discípulos de Saint-Amour se someten, otros persisten en la fidelidad a su maestro, quien será condenado al destierro por San Luis -a instancias de Alejandro IV- en 1257:

19 FRAY GRATIEN de PARIS, Historia de la fundación y evolución de la Orden de frailes menores en el siglo XIII, Buenos Aires, Dedebec, Ediciones Desclée, de Brouwer, p. 210. 
Bien avez ouï la discorde

(Ne convient pas que la recorde)

Qui a duré tant longuement,

Sept ans tout pleins entièrement,

Entre la gent saint Dominique

Et ceux qui lisent de logique ${ }^{20}$.

Además de insinuar la larga duración de la disputa entre ambos grupos, Rutebeuf nos da idea de los muchos intereses en juego:

Les prélats surent cette guerre,

Si commencèrent à requerre

L'Université et les Frères

Qui sont de plus de quatre mères,

Qu'ils leu laissassent la paix faire;

Et guerre si doit moult déplaire

A gens qui paix et foi sermonnent

Et qui les bons exemples donnent

Par parole et par fait ensemble ${ }^{21}$,

Así, pues, Rutebeuf sigue atentamente la disputa, participa de ella adhiriéndose con vigor a Guillaume de Saint-Amour y expresando esa adhesión en Le dit de Guillaume de Saint-Amour y en la Complainte de Guillaume ${ }^{22}$. En el primer caso se trata de una invectiva contra quienes han permitido y buscando la condena y exilio de Guillaume de Saint- Amour:

Prélats, je vous fais assavoir

Que tous en êtes aviliés ${ }^{23}$

En la Complainte Rutebeuf se duele del exilio de su maestro:

Séjourner lui faut en Bourgogne

Mat et confus;

De là ne se meuvra-t-il plus ${ }^{24}$,

Y supone que el exilio ha alejado del mundo las mejores virtudes:

20 RUTEBEUF, ed. G. Lafeuille, p. 85 y ss. (p. 86)./Le dit de Guillaume de Saint-Amour. «Bien habéis oldo sobre la discordia/ (No es conveniente que yo la recuerde)/ que ha durado tan largamente/ siete años completos/ entre la gente de Santo Domingo/ y aquéllos que leen [enseñan] la lógica».

21 Id., p. 85 y ss. (p. 87) «Los prelados conocieron esta guerra/ comenzaron a solicitar / a la Universidad y a los Hermanos, / que tienen más de cuatro madres / que les dejaran hacer la paz / pues la guerra debe desagradar mucho/ a las gentes que predican paz y fe/ y que dan los buenos ejemplos/tanto por palabra como por hechos".

22 Id., pp. 85 y 89.

23 Id., p. 85, v. 13. «Prelados, os hago saber que todos os habéis envil rido». No analizaremos todos los tópicos satíricos que constituyen la temática del poeta. Han sido enunciados y estudiados ampliamente por Serper, ob. cit., chapitre IV, p. 69 y ss.

24 Id., p. 92, vv. 115-7. «Deberá habitar en Borgoña/ abatido y confuso/ de allí no saldrá jamás». 
Morte est Pitié

Et Charité et Amitié;

Fors du règne les ont jetées

Hypocrisie

Et Vaine Gloire et Tricherie

Et Faux-Semblant et dame Envie

Qui tout enflamme 25

Ataca duramente a los mendicantes a quienes presenta como influyentes y siniestros consejeros de los grandes. Autores del mal consejo que ha alejado a Guillaume de Saint-Amour, que ha transformado la enseñanza en la Universidad ...

Les Frères sont or seigneurs

Des rois, des prélats et des comtes ${ }^{26}$.

Interesa pensar en los motivos de adhesión de Rutebeuf a Guillermo de Saint-Amour y a su lucha. Aunque calificado de juglar, evidentemente tenía más altas aspiraciones. Repetidas veces afirma que él no es "ouvrier de ses mains» "27. En La bataille des vices contre les vertus dice:

C'est à rimer une matière;

En lieu d'oeuvrer à ce m'atire,

Car autre ouvrage ne sais faire ${ }^{28}$

Pensamos que se refleja en ese pobre estudiante que llega a París para estudiar y conquistar un puesto en la sociedad:

Le fils d'un pauvre paysan

Viendra à Paris pour apprendre;

Tout que son père pourra prendre

Sur un arpent ou deux de terre,

Pour prix et pour honneur conquerre

Baillera le tout à son fils

Et il en demeure à exil ${ }^{29}$ bor.

Ese triste retrato da paso sin embargo a un intelectual orgulloso de su laQue esa tarea no era desdeñable a sus ojos podemos sospecharlo a través de las palabras de La mort Rutebeuf:

$2 s$ Id., p. 91, v. 72 y ss. «Ha muerto la Piedad / y Caridad y Amistad/ fuera del reino las ha expulsado la Hipocresía / y Vanagloria y Engaño/ y Falso-Semblante y dama Envidia / que todo inflaman.

26 Id., p. 104 y ss (p. 106) «Los frailes ahora son señores/ de los reyes, de los prelados y de los condes». Ver SERPER, ob. cit., 2. Le roi de France, pp. 86 y ss.

27 Id., p. 162. «Obrero de sus manosn. cerw.

28 Id., p. 104. «Rimar es una actividad / que me atrae en lugar de trabajar / pues otra obra no sé ha-

29 Id., p. 123. «El hijo de un pobre campesino / vendrá a París para aprender/para obtener compensación y honor / todo lo que su padre pueda obtener / de uno o dos arpendes de tierra/ [todo esto]/ entregará a su hijo / y él quedará arruinadow. 
Ne me fit Dieu bonté entière

Qui me donna sens et savoir

Et me fit à sa forme chère "?

Es posible que se viera como un intelectual desplazado y de ahí su identificación y fidelidad a Guillaume de Saint-Amour. Esa identificación lo lleva a enfrentarse con las órdenes religiosas, en particular con las que disputaban a los laicos el terreno intelectual en las Universidades. Es interesante destacar que Rutebeuf utiliza en el ataque las frases agresivas que ha empleado para pintar su miseria pedigüeña:

Et qui leur engraissent les panses

Du bien d'autrui, de sa substance ${ }^{31}$.

Ejemplo de autopunición y exopunición.

Considerado juglar, es evidente que Rutebeuf soportaba la desvalida condición de estos descalificados miembros de la sociedad pero participaba -lo vemos a través de sus adhesiones- de las inquietudes de sus amigos, los intelectuales laicos. Toma - para realizar el ataque de las órdenes- uno de los temas que preocupan a esos intelectuales laicos, el de la pobreza voluntaria. Interesa asomarse al problema y a la polémica porque eso puede dar la dimensión intelectual, si no en cuanto a pensamiento original, sí, por lo menos, en lo que se refiere a participación de intereses con los círculos intelectuales más calificados.

Evidentemente, el concepto de pobreza tal como se da en el Evangelio tiene que ser reconsiderado en su dimensión eclesiológica: «Si quieres ser perfecto, ve, vende todo lo que posees, dalo a los pobres y tendrás un tesoro en los cielos; luego, ven, sígueme» [Mat., XIX, 21].

Hay un enfrentamiento neto entre las nociones de pobreza moral y pobreza institucionalizada. Como dice Philippe Grand en su artículo Gérard d'Abbeville et la pauvreté volontaire en Polémiques autour de la notion de pauvreté spirituelle ${ }^{32}$ : «Si uno la define [a la pobreza] como un estado permanente de inseguridad material por asimilación a la situación concreta de los desheredados de este mundo, entonces el desgarramiento de San Francisco al morir es explicable: hay una incompatibilidad entre una institución, sustento temporal permanente y un género de vida que es precisamente la negativa a todo sostén temporal permanente. $\mathrm{Ni}$ la pobreza de Cristo ni la de San Francisco fueron anti-sociales. Pero fueron a-sociales con lo que esto comporta de inestabilidad».

Pero esta consideración referida a San Francisco no puede extenderse a los imagen?».

30 Id., p. 173. «No me hizo Dios una gran merced/ pues me dio juicio y saber/y me hizo según su querida

31 Id., p. 94, vv. 22-23. «Y que les engorden las panzas / con el bien de los otros, con su riqueza». Ver $u t$ supra.

32 Philippe Grand, Gotrand d'Abbeville et la pauerete volontaine. Polémiques autour de la notion de paurnete spiritualle. Études sur l'bistoine de la pawenete, ed. Michel Mollat, Paris, Pub. de la Sorbonne, 2 vols., 1974, t I, pp. 389-409 (p. 390). Ver además Henjía y marginalidad en «Marginalidad en la Edad Mediaw, pp. 351 y ss. 
mendicantes. Ellos están al abrigo de la pobreza porque su subsistencia está asegurada por sus conventos. Los mendicantes observan una pretendida pobreza y atacan a todos los que poseen bienes - dicen sus destractores-cuando ciertamente gozan de los bienes de la orden. Esta actitud sólo es hipócrita pues en su vida no practican la pobreza en su pleno concepto. Simplemente juegan con términos como usus y dominium, porque -como dice Gérard d'Abbeville- "Cómo se puede afirmar que las vestimentas usadas hasta el extremo o los alimentos absorbidos y digeridos pertenecen todavía al donante?" ¿Sois pobres? Ilusión o hipocresía. Pero sea. En tal caso, somos tan pobres como vosotros" ${ }^{i 4}$.

Se discute incluso acerca de la pobreza de Cristo y sus apóstoles. Los seculares llegan a la conclusión que no fueron pobres que vivieran de la caridad pública y que tuvieron dinero, puesto que cuando Cristo encuentra a la samaritana sus discípulos habían ido a buscar provisiones [Jo., IV, 8] ${ }^{35}$.

Gérard d'Abbeville -jefe de los maestros seculares luego del alejamiento de Saint-Amour- opone al ideal de pobreza material el ideal de pobreza espiritual. «La pobreza material de los mendicantes es ascética y descarnada, domina la naturaleza quebrándola; la pobreza espiritual de los seculares se encarna en la naturaleza y en la sociedad. La Iglesia, tal como es, con su poder y sus riquezas, da a los cristianos el ejemplo de la pobreza ideal" ${ }^{36}$.

El alegato de Gérard d'Abbeville no es sino un ejemplo de la discusión sobre el tema de la pobreza expresada en su dimensión institucionalizada a través de las órdenes mendicantes. Nos hemos referido a él para entender la dimensión e importancia de un tema de discusión de los grupos intelectuales. Y de qué manera Rutebeuf refleja -en tono menor- un tema que ocupaba a los más altos pensadores de la época. Su ataque contra las órdenes mendicantes sigue la línea dialéctica de estos pensadores. En La chanson des ordres dice:

Tant d'Ordres avons jà

$\mathrm{Ne}$ sais qui les songea:

Ainz Dieu tels gens n'onja

N'ils ne sont ses amis.

Papelards et béguins

Ont le siècle bonni.

Frères Prédicateurs

Sont de moult simple atour

Et s'ont en leur détour,

Sachez, maints parisis.

Papelards et béguins

Ont le siècle bonni.

33 Id., p. 400.

34 Id., p. 400.

35 Id., p. 401.

36 Id., p. 404. 
Et les Frères Menus

Nous ont si près tenus

Que ils ont retenu

De l'avoir tout aussi

Papelards et béguins

Ont le siècle bonni.

Qui ces deux n'obéit

Et qui ne leur gehit

Tout ce qu'il oncques fit,

Tel bougre ne naquit.

Papelards et béguins

Ont le siècle bonni.

Assez disent de bien,

$\mathrm{Ne}$ sais s'ils en font rien;

Ceux de la Trinité

Ont grand'fraternité;

Bien sesont acquittés:

D'ânes ont fait roussins

Papelards et béguins

Ont le siècle honni.

Et les Freres Barrés

Eux sont gras et carrés;

Ne sont pas enserrés:

Je les vis mercredi.

Papelards et béguins

Ont le siècle bonni.

...

Béguines avons mont

Qui larges robes ont;

Dessous les robes font

Ce que pas ne vous dis.

Papelards et béguins

Ont te siècle bonni ${ }^{37}$.

37 RUTEBEUF, ed. G. Lafeuille, p. 119. *Tantas Órdenes tenemos ya / que no sé quién pudiera imaginarlas / Pero Dios no aprecia a tales gentes/ ni ellos a sus amigos./ Falsos devotos y beguinos/odian al mundo.// Frailes predicadores/ son muy simples en el vestir/ pero, sabedlo, tienen en lugar oculto/ muchos parisienses / monedas de París / / Falsos devotos y beguinos/ odian al mundo// Y los Hermanos Menores/ nos han tenido tan cerca/ que incluso han retenido/ todo el haber./ Falsos devotos y beguinos/odian al mundo.//No ha nacido ningún sinvergüenza/ que no 
En L'état du monde critica la mendicidad de los religiosos y su espíritu de avaricia ${ }^{38}$ :

Après ce sont les Mendiants

Qui par la ville vont criant:

«Donnez, pour Dieu, du pain aux Frères!»

Plus en $y$ a de ving manières.

$\mathrm{Ci}$ a dure fraternité,

Car, par la sainte Trinité

L'un des couvents voudrait de l'autre

Qu'il fut en un chapeau de feutre

Au plus périlleux de la mer:

Ainsis s'entr'aiment les avares.

En su composición Des jacobins ${ }^{39}$ critica la tergiversación del concepto de pobreza:

Quand les Frères Jacobins vinrent premier au monde,

Si étaient par semblant et purs et nets et mondes,

Longtemps ont or été si comme l'eau profonde

Qui sans courir tournoie tout autour à la ronde

Premier ne demandèrent qu'un peu de repostaille

Avec un peu d'estrain ou de chaume ou de paille;

Le nom Dieu sermonnaient à la pauvre piétaille,

Mais or n'ont plus que faire d'home qui à pied aille.

Tant ont eu deniers et de clercs et de lais

obedezca a esas dos [Órdenes]/ y no les confiese [acepte]/todo lo que jamás hicieron/Falsos devotos y beguinos/odian al mundo// Hablan muy bien / No sé si actúan bien / Los de la Trinidad / tienen una gran fraternidad/ se han liberado bien/ han convertido los asnos en rocines / Falsos devotos y beguinos / odian al mundo// Y los Hermanos cruzados / son gordos y cuadrados / no están encerrados en absoluto/Yo lo ví el miércoles/ Falsos devotos y beguinos / adian al mundo//.... Se ven muchas beguinas / que llevan largas vestiduras/debajo de los vestidos hacen lo que yo no os digo / Falsos devotos y beguinos / odian al mundon.

38 Id., p. 125. «(...) Luego están los mendicantes/ que van gritando por la ciudad/'dad pan a los Hermanos / frailes/ por Dios!' / Hay más de veinte maneras/ Esta es una dura fraternidad/ pues, por la Santa Trinidad/ uno de los conventos quisiera que el otro / estuviera en un sombrero de fieltro / en lo más peligroso del mar/ así se ayudan entre sí los avarosn.

39 Id., p. 111 . «(...) Cuando los Hermanos Jacobinos vinieron por primera vez al mundo / eran en su aspecto puros, claros y limpios/ por largo tiempo han estado así como agua profunda / que sin correr gira alrededor, en redondo / en primer término, no solicitaron sino un poco de reposo/ con un poco de paja o de bálago /Predicaban el nombre de Dios a los pobres creyentes/ pero ahora no tienen nada que hacer con hombre que vaya a pie./ Han obtenido tantos denarios de clérigos y laicos/tanto por ejecuciones / testamentarias, / por limosnas y legados/ que han transformado las casas humildes en grandes palacios / al punto que un hombre con la lanza en la mano, allí daría una carga / (...) Por el amor de J.C. dejaron la camisa / y tomaron la pobreza que correspondía a la Orden / pero ellos han tratado a la pobreza de otra manera / predican la humildad, que han derribado/(...) No hay en este mundo hereje ni herético/ ni tampoco maniqueo, valdense o sodomita/ que si se viste con el hábito en que habita el falso devoto / no se lo considere ya como santo o ermitañon. 
Et d'exécutions, d'aumones et de lais,

Que des basses maisons ont fait si grands palais

Qu'un homme, lance au poing, y ferait un eslais.

(....)

Pour l'amour Jésus-Christ laissèrent la chemise,

Et prirent pauvreté qu'à l'Ordre était promise;

Mais ils ont Pauvreté glosée en autre guise:

Humilité sermonnent, qu'ils ont en terre mise.

(....)

Il n'a en tour ce mond bougre ni hérétique

$\mathrm{Ni}$ fort popelican, vaudois ni sodomite,

Si il vêtait l'habit où papelard habite,

Qu'on ne le tînt déjà à saint ou à ermite.

Rutebeuf aparece con una dimensión mayor que un simple juglar. Se adhiere a la persona de Guillaume de Saint-Amour y a la doctrina que sustenta. Participa de una contienda que sopesa valores fundamentales de su sociedad. Su dimensión intelectual no parece coincidir con su suerte económica. Mendiga y tiene que agradar para vivir. Agrada y acusa. De ahí su actitud crítica que, como hemos visto, no siempre se vuelve contra los otros sino a veces también contra sí mismo. La autopunición deriva precisamente de una concesión que hace a los valores imperantes: el poeta tiene que adecuarse a la sociedad -que lo rechaza y que rechaza- en la adulación, en el pedido, en el ademán pedigüeño...

Evidentemente es un disidente nostálgico: «ya que el mundo ha cambiado demasiado / que se ha extrañado de toda clase de bienes» ${ }^{40}$. Desea el retorno de esos valores perdidos, cree que la sociedad, esa sociedad en que le toca vivir, lo relega injustamente. $Y$ esa injusticia tiene su origen en esa transformación. Frustración, pues, grito de acusación y ademán de aceptación, sentimientos y actitudes contradictorios en este disidente que también es cambiante en su mensaje, humilde, agresivamente plañidero, francamente acusador y ácidamente burlón...

NILDA GUGLIELMI Universidad de Buenos Aires Consejo de Inv. Científicas, Argentina.

40 Id., p. 128. 